\title{
Third Eye for Blind
}

\author{
Azra Batool \\ Department of Electronics and Communication Engineering, \\ Sharda University, \\ Greater Noida(U.P) ,India \\ sayedsam88@gmail.com
}

\author{
Shaheen Naz \\ Department of Electronics and Communication Engineering, \\ Sharda University, \\ Greater Noida(U.P), India \\ shaheen.naz@sharda.ac.in
}

\begin{abstract}
Vision is the most beautiful and important gift from God to all his creatures especially for human beings. But unfortunately there are some people who lack this beauty and are unable to capture the beauty of this world from their own eyes. Third eye for blind is a development which involves various areas such as, software engineering, hardware designing and science that enables visually impaired persons to see and explore the world confidently and independently by recognising the neighbouring objects by using ultrasonic waves and inform the person with a beep ring or vibration. As per WHO(world health organisation) $\mathbf{2 . 2}$ billion people suffer from vision impairment. They are facing troubles in their lifestyle. This device can act as an innovation for the visually impaired people. From a lot of advantages we found the property of being reasonable within a limited cost, a very important merit of the project. The Arduino Pro Mini 328 board is tied like a band. This is provided with ultrasonic sensor, consisting of module. By utilising this sensormodule, the person is able to see the objects near them and can travel effectively. At any point where this sensor senses any object, it informs the person by beep-sound or vibration. In this way this becomes a computerized gadget. Accordingly this gadget will be of utmost use for the blind people and can allow them to move from any place with confidence.
\end{abstract}

Key Words: Arduino, Wearable band, buzzer, blind, people, compact, ultrasonic, obstacles, google street-view

\section{INTRODUCTION}

As per the definition of blindness, we mean the person without sense of sight. A blind person has no ability to see anything. While struggling for the different levels of comforts of the general population, we have reached to a point where we have started to completely ignore the people who are living a miserable life due to lack of vision. They face enormous challenges in their daily lives and hence end up living a dependent life. They experience a completely different life from the normal people and experience detached and uninterested conduct towards them for being physically disabled. They need other individuals for their movement from one place to another. Sight is the basic sense of life and therefore a person's movement from place to place in this condition is a major challenge for the visually impaired .

The target of this task, This project for the blind or visually impaired person will provide a gadget that is helpful to them as well as the persons who depend on any individual due to lack of sight. Third eye for blind task can be an innovation for the sightless individuals, it will help them to move from here and there and among different places with confidence by knowing the nearest obstructions while wearing the band which leaves the ultrasonic waves which inform the person with beep-sound or vibration. It can let the person who is not able to move and distinguish even snags due to lack of vision. They just have to put on the gadget as a band/bracelet or it can be adjusted on the dress on their body.

As per $\mathrm{WHO}$ (world health organisation) 2.2 billion people suffer from vision impairment. They experience a lot of troubles in the daily lives. This device can be an innovation for the physically disabled or blind individuals. The people with physical disability used the common way that is white cane previously that was also efficient, but it had lot of limitations.

Second approach is, having a pet ,like a dog, though it is costly but is helpful .Therefore this task, Third eye for blind will be developed as a moderate, very productive approach to help the blind person traverse with confidence and more interest. The device acts as an innovation for blinds which helps to solve all issues. At Present, enormous techniques and brilliant innovations are available for the physically disabled people, almost all of these devices have solved some of the issues for the sightless people but there exist many demirits like they require considerable measures of preparing and and high maintenance. The uniqueness of the proposed advancement is, it is fair for everyone, the total cost being under $\$ 20$ or 1500 INR. In the market, no such devices are available that look like an item that can be worn with so much less effort, clarity. By increasing the usage of the gadget and the upgrading the changes in the model, it would definitely be profitable to the people with less or no vision at all. The basic mechanical gadget that is the strolling stick is manufactured so that it can be used in identifying stationary objects on floors, unbalanced surfaces, holes, steps using the basic mechanical matter. The gadget is fine, convenient but because of compact area it cannot be used for vast snag identification

The device works like radar, orientation of the device uses the ultrasonic waves and collect them to note the altitude, direction or also velocity of that object. The separation among the object and person is assessed on the travelling of the wave. Nevertheless, all present systems advise the person about the closeness of the protest at a certain space in forefront or nearby the individual. 
The interesting aspects enable the unsighted person in distinguishing snags and grants him access to choose his path properly with no issue. This device can help the person in identifying any type of hindrance like a snag. For surviving the earlier stated restrictions this project work provides primary, productive, customizable and effective solution to the visually impaired.

\section{LITERATURE SURVEY}

In the past few years, there has been innovations and development of various techniques and devices or gadgets guiding visually impaired people, thus towards attaining their independent or free movement around the surroundings without any other individual's support. Few parameters are there but they are having some limitations and restrictions.

D. Dakopoulos, N.G. Bourbakis, "Wearable obstacle Avoidance Electronic Travel Aids for Blind; A Survey" proposed that a relative survey among mobile obstacle detection systems in order to inform the research community and users regarding the abilities of this project and regarding the innovation in adaptive technology for the sightless people. This study is based on different attributes and performance specification of this system that arranges them in categories, offering quantitative-qualitative analysis.

M.A Ungar S[5]. He proposed methods for the unsighted people of urban areas. But they didn't consider the people who cannot afford equipments of high cost. This drawback overcomes in Third eye for blind.

Ms Pooja Sharma[6]. She analysed that objects can be detected, but there are drawbacks in terms of angles and distance . On the other hand, third eye for blind has a wide angle for the detection which can be widened with respect to the range of the sensor.

Hugo Fernandesc, Joảo Barroso"Blind Guide: an ultrasound sensor based body area network for guiding blind people". The research introduces supportive formula for sensing obstacles for the sightless persons who generally take help of white-cane or the pet dog, thus for the detection of obstacles by using this device provides a proper solution to the blinds. Based on the Body Area Network of ultrasonic sensors that generate sound-based response, this solution is given. The Body Area Network can be inserted inside cloth fabric, emancipating sightless person from utilizing the seeing-eye dog or that white-cane .

Today's Innovative world is providing many solutions to the visually impaired for example; white-cane having a tip for assisting the movement of the blind people. The cane has different types used in today's technological world in the form of white cane, laser cane and smart cane. Dogs trained for this purpose are too expensive and unaffordable for certain people[9]. The study discovered [10] that the remote guidance system being very hard to move hence this device will act as most optimized version.

\section{SYSTEM ARCHITECTURE}

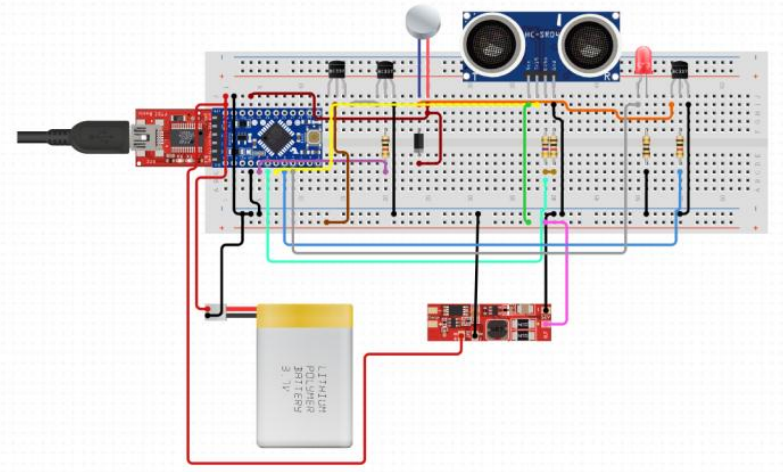

Fig. 1. Circuit Diagram(1) of the Device

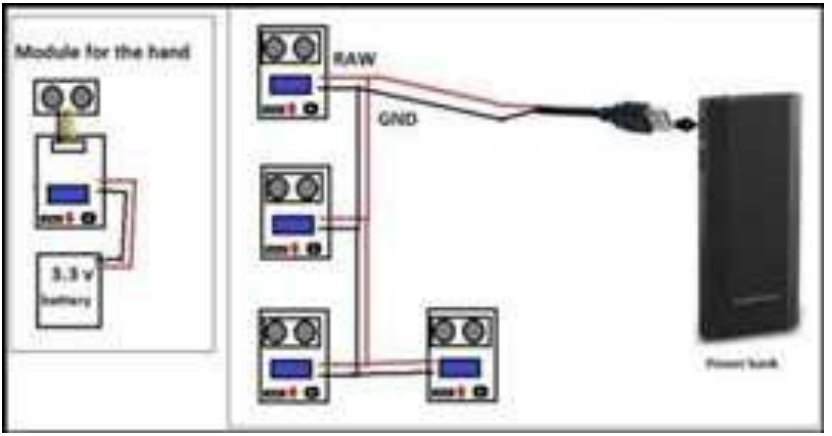

Fig. 2. Detailed Circuit Diagram(2)

This band ,buzzer ,LED's, ultrasonic sensors all are connected to the arduino board. The connections are established with the help of soldering.

\section{PROPOSED WORK}

The shape of the gadget that is to be worn like band or we can say like a material by the blind person depends on an surprising wearable gadget in light of the Arduino board. The project can be made by five ultrasonic sensors, consisting five modules linked to different parts of the body. The five modules can be set as two for shoulders, two for knees and one for hand.

\section{A. Module 1-vibration mode}

whenever the obstacle is nearer, it will be sensed by the module and a vibration along with the beep sound will be felt by the person which will help to traverse in a better way.

\section{B. Module 2-Buzzer mode}

It will produce a beep sound on sensing the obstacle and if the way is clear then it won't produce any sound.

C. Module 3-Use of google street-view for providing audio feedback to the blind person.

D. Module 4-GPS(Global Positioning System) for live tracking of the person

This module will follow the current location of the unsighted individual. 


\section{WORKING OPERATIONS}

The suggested system consists of components like Arduino mini pro, ultrasonic sensor, vibrating motor, buzzers, perf board or zero PCB for the detection of obstacles and there is need of few components like red coloured LED, switches, jumper wire, power bank, male and female header pins, 3.3 volt battery, with which user identifies an object. some rubber is used to make the device wearable like a bracelet/band.

The connections of this gadget are developed as follows:

The -ve terminal of led, buzzer and vibration motor are grounded with the ground of Arduino. Led's +ve terminal, central terminal of switch is linked to pin number 5 of the Arduino. The buzzer's +ve terminal has to be connected to the switch's $1^{\text {st }}$ terminal and +ve terminal of the vibration motor is connected to the switch's $3^{\text {rd }}$ terminal

Now the connection of ultrasonic sensor module is that The VCC pins of both the sensor module and the Arduino are connected and also the GND of both are connected respectively. Trig pin of ultrasonic sensor and pin no 12 of the Arduino are connected together. The echo pin of ultrasonic sensor is attached to the pin no. 12 in the Arduino. A switch is connected which is used for the selection of mode i.e buzzer mode or vibration mode.

Cut the PCB in $5 \times 3 \mathrm{~cm}$ dimension and solder the female headers on the board for Arduino. Now solder the buzzer . Glue is used to connect the motor and wires are soldered to it. Now connect the LED. After connecting the LED, Connect the switch. For ultrasonic sensors and input of the battery, connect the headers. Then solder all the components and connect the Ultrasonic sensor and Arduino to the PCB. Attach the elastic band to every module. Using 4 jumper wires, connect the ultrasonic sensor to the board so that a module for the hand can be constructed and connect a 3.7 volt mobile battery to this module. Now the elastic band is connected. Lastly, after the connections of the Arduino board are done, upload the program to every Arduino board and give power supply to another 4 modules.

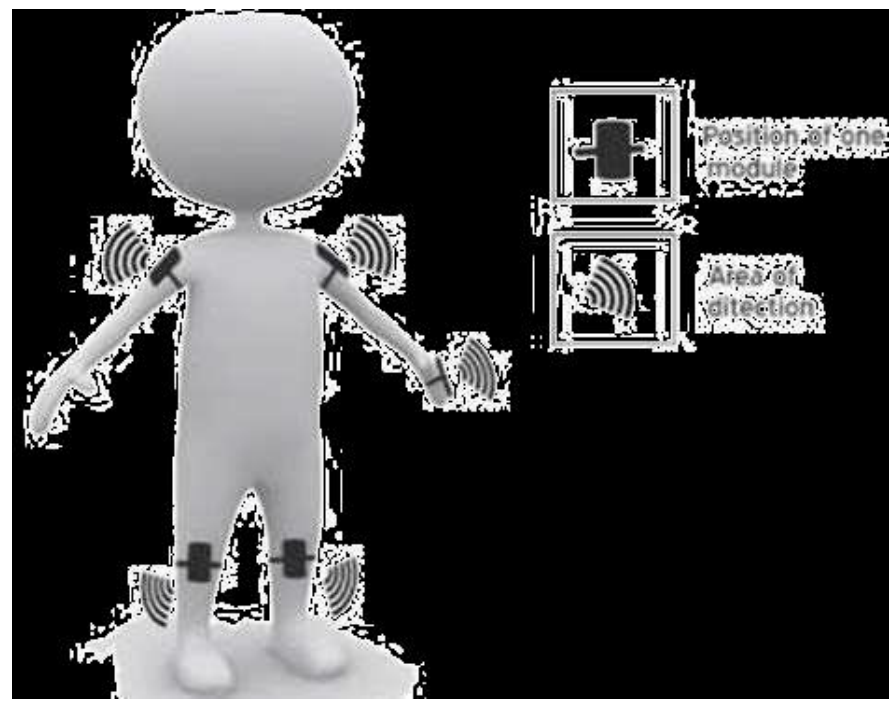

Fig. 3. Position of the Modules

\section{SYSTEM FLOW}
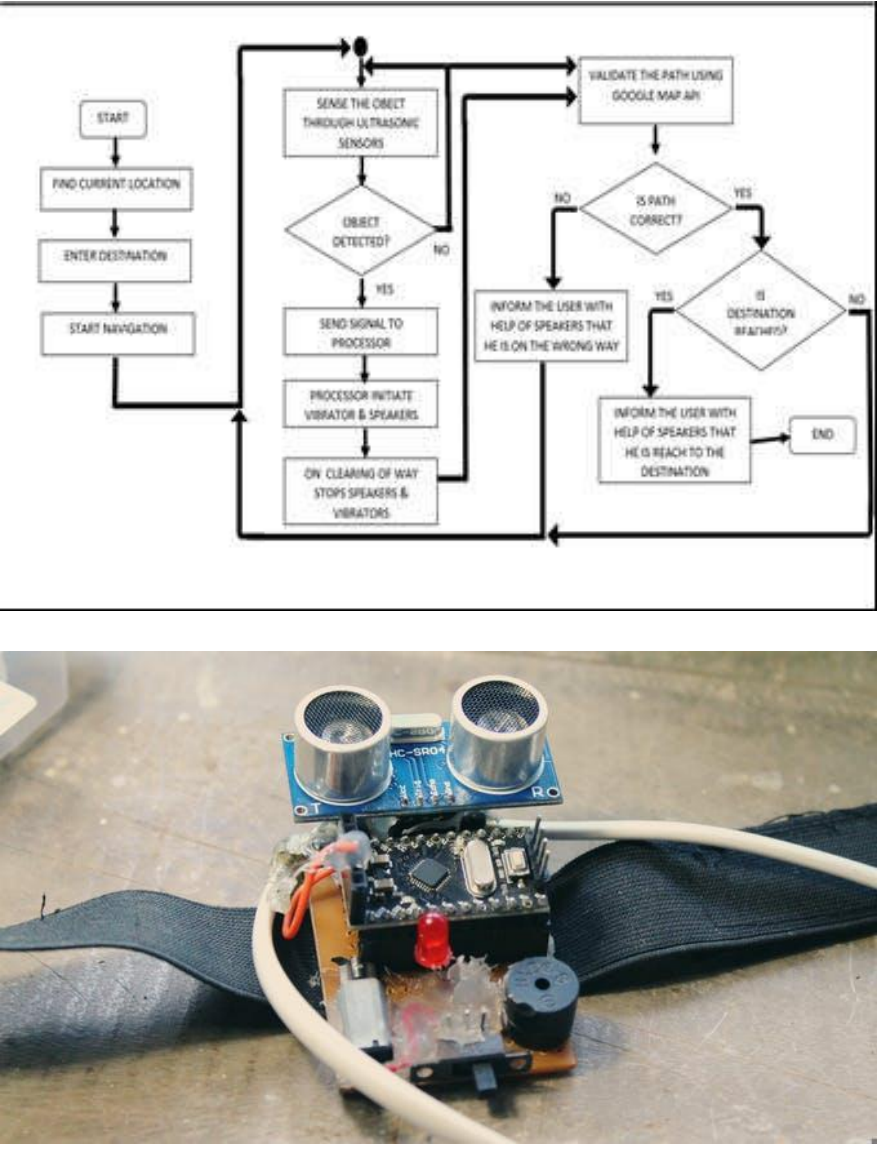

Fig. 4. Module for Hand

TRANSRECEIVER: The transmitter emits ultrasonic waves, these waves hit the obstacle if present in the path, and then are reflected back after by the obstacle. The receiver receives this reflected wave. The ultrasonic sensor consists of one transmitter and receiver. The total time taken for the ejecting and collecting the ultrasonic wave can be evaluated which is then involved in calculating the distance between sensor-module and the object.

The equation for evalvating the sensor to object distance is given below:

$$
\mathrm{S}=\left(\mathrm{H}^{*} \mathrm{~V}_{\mathrm{s}}\right) / 2
$$

Where, $\mathrm{S}=$ distance in centimetre, $\mathrm{H}=$ High time of pulse width, $\mathrm{V}_{\mathrm{s}}=$ velocity of sound in centimetres $/$ second $=343 \mathrm{~m} / \mathrm{s}$ in air

The sensors used in the middle section belt need to be placed in the area where the US beats of sensor are not jumbled Sensors have Field view of around $\pi / 3$ radians for 1.2 metre pull out, when the gap from the sensor increases, the inclusion edge declines.

In this way, along with the above lines Third eye for the blind will be considered for blind individuals thus can make it effortless and advantageous as it will be a device that can be 
worn and therefore can be helpful for the person for travelling, also knowing the hindrances during walk smoothly .

\section{RESULT \& DISCUSSION}

The system is created and designed for visually impaired people. This device helps the visually impaired people to handle several states and responds to the user in every environment. All the conditions can be easily met by the blind individual using ultrasonic sensor and the Arduino board.

This device will help the visually impaired people to know about the obstacles in every direction.

1. CASE 1: If the obstacle lies on the west/left side of the person, the device will let the person know that there is an obstacle on the west/left side.

2. CASE 2 : If the obstacle lies on the east/ right side of the person, the device will let the person know that the obstacle lies on the east/right side.

3. CASE 3 : If the obstacle lies in front of the user, it will tell the user that there is an obstacle in front of the user.

And similarly the person will know about the obstacle in all the directions like back, left, right etc.

\section{CONCLUSION}

Thus, the project, Third Eye for blind people is made sightless individuals to live independently, so as to perform their daily activities easily and more confidently with high level of safety. This Arduino based concept for the blind people is simple, cheap and can be easily carried and maintained. This system is able to scan and detect the hindrances in all directions irrespective of the height or depth the object lies at. With this project, if the construction is done properly, the blind can enjoy the taste of sight and can move freely from one place to another without assistance of the other individual.

\section{FUTURE ENHANCEMENT}

In future with the advancement of quicker response of sensors, like the usage of top notch sensors it can be made highly useful and also the modules that one needs to wear as a bracelet or on any other part of the body can be transformed into a wearable clothing like a coat, so that it can be made fit for working and there can be more advancement in this device for instance we can use piezeo electric plates in the shoes of the user which can generate sufficient electricity that the modules can run on.

\section{REFERENCES}

[1] Johann Borenstien ,Shraga Shovel, Iwan Ulrich. Guide Cane and the Nav Belt, IEEE Transactions on Robotics \& Automation. 2003; 10(1):920 .

[2] N.G. Bourbakis, D. Dakopoulos. "Wearable Obstacle Avoidance Electronic Travel Aids for Blind: A Survey", IEEE Trans. Systems Man and Cybernetics Part C: Applications and Reviews, vol. 40, no. 1, pp. 25-35,2015.

[3] Hugo Fernandesc , João Barroso "Blind Guide: an ultrasound sensorbased body area network for guiding blind people ",6th International Conference on Software Development and Technologies for Enhancing Accessibility and Fighting Infoexclusion (DSAI 2015)

[4] Sabarish S. Navigation Tool for blind people using Microcontroller, International Journal of Engineering and Advanced Technology (IJEAT), 2013; 2(4):139-143.

[5] Espinosa MA, Ungar S, Ochaíta E. Blades comparing methods for Introducing Blind and Visually Impaired People to unfamiliar urban environments., Journal of Environmental psychology. 1998; 18:277-287.

[6] Pooja Sharma, Shimi SL, Chatterji S. A Review on Obstacle Detection and Vision, International Journal of Science and Research Technology. 2015; 4(1):1-11.

[7] Tahat AA. A wireless ranging system for the blind longcane utilizing a smart-phone, in Proceedings of the $10^{\text {th }}$ International Conference on Telecommunications. (ConTEL '09), IEEE, Zagreb, Croatia, June. View at Scopus. 2009, 111-117.

[8] Bolgiano D, Meeks Jr E. A laser cane for the blind, IEEE Journal of Quantum Electronics. View at Google Scholar. 1967; 3(6):268.

[9] Amjed Al-Fahoum S, Heba Al-Hmoud B, Ausaila Al- Fraihat A. A Smart Infrared Microcontroller-Based Blind Guidance System", Hindawi Transactions on Active and Passive Electronic Components. 2013;3(2):1-7. 